\title{
US women in thoracic surgery: reflections on the past and opportunities for the future
}

\author{
Ourania Preventza ${ }^{1}$, Leah Backhus ${ }^{2}$ \\ ${ }^{1}$ Department of Cardiovascular Surgery, Texas Heart Institute, Houston, TX, USA; Division of Cardiothoracic Surgery, Michael E. DeBakey \\ Department of Surgery, Baylor College of Medicine, Houston, TX, USA; ${ }^{2}$ Division of Thoracic Surgery, Department of Cardiothoracic Surgery, \\ Stanford University, Stanford, CA, USA \\ Contributions: (I) Conception and design: All authors; (II) Administrative support: All authors; (III) Provision of study materials or patients: All \\ authors; (IV) Collection and assembly of data: All authors; (V) Data analysis and interpretation: All authors; (VI) Manuscript writing: All authors; (VII) \\ Final approval of manuscript: All authors. \\ Correspondence to: Ourania Preventza, MD. Division of Cardiothoracic Surgery, Michael E. DeBakey Department of Surgery, BCM 390, One Baylor \\ Plaza, Baylor College of Medicine, Houston, TX, USA. Email: preventz@bcm.edu.
}

\begin{abstract}
Herein, we examine the state of women in thoracic surgery from the United States (US) perspective in terms of our past, present, and opportunities for the future. We explore the achievements of the first three women certified in thoracic surgery in 1961 and describe the progress made resulting in the current state. Women constitute slightly more than $50 \%$ of all medical students in the US, yet women remain underrepresented in thoracic surgery. The disparity is most notable for female representation in senior academic leadership positions, reflecting stagnation in progress. The lack of gender equity has important implications for projected workforce shortages and patient safety in cardiothoracic surgery. Recent organized efforts in scholarships and leadership training, as well as increasing awareness and mentorship, may herald progress on the horizon. Ultimately, however, engagement of leadership and top-down change are needed to achieve equity and, thereby, to improve patient health and satisfaction.
\end{abstract}

Keywords: Thoracic surgery; surgical workforce; unconscious bias; gender equity

Submitted Mar 23, 2020. Accepted for publication Apr 24, 2020.

doi: $10.21037 /$ jtd.2020.04.13

View this article at: http://dx.doi.org/10.21037/jtd.2020.04.13

\section{Historical perspective of women in thoracic surgery}

The history of women surgeons spans more than 5,500 years. According to the Iliad, in Ancient Greece, women performed various surgical techniques, attended births, and treated the wounds of warriors (1). In modern times, after formal medical schools were established in the United States (US), women initially were excluded from studying medicine. Drs. Elizabeth Blackwell [1821-1910], Emily Blackwell [1826-1910], and Marie Elizabeth Zakrzewska [1829-1902] were pioneers as 3 of the first American women physicians. They established the New York Infirmary for Women and Children in 1857, one of the first hospitals for women in the US (2). In doing so, the three were pivotal in the advancement of American women in the field of surgery $(3,4)$.

The history of the modern era of thoracic surgery began with the first organizational meeting of the Board of Thoracic Surgery [BTS, which became the American Board of Thoracic Surgery (ABTS) in 1971], held in the US in 1948 (5). The first written and oral board examinations of the BTS took place in August and October the next year. The BTS's first administrative assistant was a woman named Louise Sper, and much of the Society's initial work was performed in Louise's kitchen. The first woman director, vice chair, and chair of ABTS [1997-2007] was Carolyn Reed. In 1961, 12 years after BTS's first examination, Nina Starr Braunwald, Ann McKiel, and Nermin Tuttunji became the first three women to be certified by the BTS. Earlier, in 1943, Myra Adele Logan [1908-1977] became 
the first woman surgeon to operate on the heart (in only the ninth heart operation yet performed at that time) (6).

Despite these pioneering firsts, there was very little change in the gender demographics of thoracic surgery in the ensuing 20 years, with only 10 additional women becoming board certified by 1980 (7). The Women in Thoracic Surgery organization was founded by Leslie Kohman (8), an academic thoracic surgeon, in 1986, holding its inaugural meeting at the annual meeting of the Society of Thoracic Surgeons (STS) that year. One of the organization's main foci was to mentor young women thoracic surgeons and enhance their educational and research opportunities in response to a growing need within the specialty.

\section{Present}

By 2011, 50 years after certification of the first three women thoracic surgeon pioneers, more than 200 women had been certified by the ABTS. By 2018, 338 women were certified, accounting for a little more than $3 \%$ of all boardcertified thoracic surgeons at that time. Even more sobering is the fact that women now make up $52 \%$ of all US medical school students, and $41 \%$ of general surgery residents, yet only $20 \%$ of thoracic surgical trainees (9). According to the American Association of Medical Specialties (AAMC) Physician Specialty Data Report published in 2017, among 4,411 total active thoracic surgeons, women represented only $7.0 \%$, with thoracic surgery having the secondto-lowest percentage of active female physicians after orthopedic surgery (10).

The numbers are even more disparate when one considers the breakdown by subspecialty for women in adult cardiac, congenital heart, and pure thoracic surgical practice. According to a report from the STS/American Association for Thoracic Surgery (AATS) Thoracic Surgery Practice and Access Task Force, in 2010 women comprised $3.4 \%$ of adult cardiac, $5.2 \%$ of congenital heart, and $7.9 \%$ of general thoracic surgeons (11). A more recent survey reported numbers that were slightly higher, but the exact percentages are not clear because of the survey's low response rate (12). When Rosati et al. examined the characteristics of cardiothoracic surgeons practicing at the "18 top cardiothoracic centers," women represented only $7.3 \%$ of cardiothoracic surgeons as a whole, and $5.1 \%$ of cardiac surgeons versus $12.7 \%$ of thoracic surgeons (13). Examining the online archives from the Society of Thoracic Surgeons' annual meetings [2015-2018], Olive et al. found that although representation of women has increased in the cardiothoracic surgery workforce, representation among academic leadership and senior-level authorship has remained stagnant (14). Lack of gender equity in thoracic surgical leadership often engenders a response by the same leaders that the root cause is a "pipeline issue", in that low numbers of women entering into the field at the beginning of their training translates into low numbers in senior leadership roles (15). Admittedly, there are data to support this; however, the argument is a generalization of a multifactorial issue. It fails to acknowledge the multiple forces at play in creating and perpetuating the current diversity landscape. One of the most compelling forces is that of burnout leading to attrition among those venturing into the specialty. A leaky pipeline due to a negative work environment and burnout is a well-documented problem for both young women in surgical training and senior-level female physicians, leading to attrition among even the most inspired $(16,17)$. The notion that few women enter into thoracic surgery because of a lack of interest in the specialty is often over-emphasized, leading to apathy regarding the problem among leadership.

A crucial question is why we care about the number of women in our specialty or achieving gender equity at all. One of the main reasons to support gender equity is the projected future shortage of cardiothoracic surgeons in the US to care for our aging population. According to the AAMC 2019 update, the demand for physicians will exceed the supply by 2032, with the primary driver being population growth and aging (18). By 2032, the US population aged 65 years or older is projected to grow by $48 \%$, and a shortfall of 14,300-23,400 doctors is projected for surgical specialties. Even in the best-case scenario, in which population health goals such as low cholesterol, healthy diet, blood pressure control, and blood sugar control are achieved, the longevity associated with improved population health would result in greater demand. In addition, between 2012 and 2017, the number of active physicians practicing thoracic surgery (adult cardiac, congenital heart, and general thoracic surgery) in the US decreased by $3.8 \%$ - whereas, for example, the number of interventional cardiologists increased by $58 \%$ (19). In a 2018 survey of the US surgeon workforce, $66 \%$ of subspecialty surgeons less than 60 years of age and $62 \%$ of those aged 60 years or older reported that they were considering leaving clinical practice by 2020 (20).

For these reasons, recruiting qualified cardiothoracic surgeons of all genders is very important, and women 
represent a largely untapped resource, given the nearly equal gender distribution among US medical students. Yet, the 2018 survey (20) indicated that male surgeons were significantly less likely than female surgeons to recommend surgery to a female medical student, whereas no difference was seen for male medical students. This discrepancy needs to be rectified if we are to overcome the AAMC's projected shortfall for surgical subspecialties.

Female representation in thoracic surgery is also important to ensuring that women's health remains an active priority among physicians and researchers. Current research findings highlight the importance of cardiovascular disease in women, with heart disease being the leading cause of death for women in the US (21). A 2011 report regarding sex and gender differences in coronary artery disease described physiological, psychological, and treatment differences, as well as differences in outcomes after myocardial infarction and coronary artery bypass (22). When Spiliotopoulos and colleagues examined whether sex affected outcomes after open thoracoabdominal aortic aneurysm repair, they found that although propensitymatched groups of men and women had similar outcomes and adverse event rates, there were important differences in predictors of operative death and adverse events (23). Sexbased differences in outcomes have also been reported for thoracic organ transplantation, and further research into sex-specific regimens is needed $(24,25)$.

Furthermore, female physician gender has been associated with better clinical outcomes and important patient safety metrics. In a large study based on Medicare claims, elderly patients treated by female physicians tended to have lower 30 -day mortality rates $(11.07 \%$ versus $11.49 \%)$ and lower readmission rates $(15.02 \%$ versus $15.57 \%)$ for all medical conditions than elderly patients treated by male physicians (26). Within thoracic surgery, patient-physician gender disagreement has been linked to greater mortality among female patients being treated for acute myocardial infarction. Perhaps the most striking finding in this study, however, was the observation that male physicians with more female patients and more female colleagues had more success treating female patients (27). Thus, the benefits of gender diversity are not limited to the individual female physician and patient; rather, they can be realized by all members of our healthcare system.

Patient satisfaction is another important reason to increase the representation of women in thoracic surgery. From the internal medicine literature, among 504 patients in a series of studies regarding the influence of gender on doctor-patient interaction, the patients of female doctors were more satisfied than those of male doctors, even after adjustment for patient characteristics (including patient gender) and physician practice style (28). Patient and provider interactions are also an important determinant of patient compliance with treatment and willingness to participate in clinical trials. In more than 150 clinical trials cited in the 2007 update of the American Heart Association Guidelines for Cardiovascular Disease Prevention in Women (9), women accounted for less than $30 \%$ of participants (29). Women were least well represented in trials of treatments for heart failure (29\%) and coronary artery disease (25\%), even though women account for $51 \%$ and $45 \%$ of patients with those diagnoses, respectively.

In oncology, clinical trial participation is critical to drug discovery and development. For women, this is particularly important with regard to the study of lung cancer; compared with men, women have significantly lower rates of success in smoking cessation and higher rates of lung cancer among never smokers. Nonetheless, there has been little investigation dedicated to exploring the influence of hormones on important clinical outcomes (30-32).

\section{Future}

Given the reported benefits outlined above, what are the current barriers to prioritizing and achieving gender equity in thoracic surgery, and how we can overcome them? According to a 2012 Women in Thoracic Surgery report, inadequate support is a significant barrier to retention, especially for women certified in cardiothoracic surgery since 2000, whereas demand on time was the greatest barrier for women certified before 2000 (7). In the latest report from the American College of Surgeons (20), among surgeons less than 60 years of age who were considering leaving medicine, personal time requirements $(73 \%)$, overall work demand (77\%), overall stress (79\%), sense of isolation $(43 \%)$, harassment $(37 \%)$, inadequate career advancement $(23 \%)$, and inadequate mentoring $(12 \%)$ were all important reasons (20). In addition, in an online confidential survey distributed through the Association of Surgeons of Great Britain and Ireland, more than half of women responders reported experiencing discrimination, while one quarter perceived a "glass ceiling" in surgical training (33). These data $(20,33)$ suggest that retaining qualified surgeons requires an environment of inclusivity, a sense of belonging, support, and opportunities for advancement.

These numbers, as sobering as they are, are not unique 
to medicine or cardiothoracic surgery. Bias (implicit or otherwise) is well-documented in contributing to unequal opportunities and lack of career advancement among women and minorities (15,34-36). According to the Rockefeller Foundation and the Global Strategy Group, more than $70 \%$ of Americans believe that women are less likely to be promoted to mid- and senior-level positions, and more than $80 \%$ of Americans believe that men in leadership positions do not prioritize hiring women or promoting them to top positions (37). In addition, only $25 \%$ believe that women have a "great deal" of opportunity to serve in leadership positions in the American workplace, and these numbers are even lower for certain professional fields such as science and technology.

Of course, the main question is how we turn the tide and change the culture to create a more inclusive environment. There is no question that diversity of thought is inextricably linked to excellence in performance and innovation. Recognizing this, the STS recently championed the importance of diversity in thoracic surgery (38). Before an organization can begin creating solutions to support an inclusive environment, it must first recognize the current disparity and its importance. Cultural competency in healthcare has been defined as "understanding the importance of social and cultural influences on patients' bealth beliefs and behaviors; considering how these factors interact at multiple levels of the bealth care delivery system" (39). A recent survey of surgeon members of the STS (36) reported a high rate of self-reported cultural competency among thoracic surgeons despite extensive published evidence documenting a significant lack of cultural dexterity among health care providers in nearly all populations studied. This may well represent our cognitive blind spot where the deficit-in this case, cultural competency - is not recognized. Unless we acknowledge the problem and the crucial importance of finding solutions, progress will be difficult to make. Unconscious bias among managers, lack of female role models, lack of incoming talent, low confidence among women in the field, and lack of work-life balance have been perceived as the main interconnected barriers to hiring and promoting women in industry (40). Without a doubt, seeing what is achievable by senior leaders boosts the confidence and aspirations of their juniors; thus, the paucity of women in senior positions acting as mentors and sponsors disadvantages junior-level women disproportionately relative to their male counterparts.

Mentorship can be a great tool for all cardiothoracic surgery trainees and junior surgeons. Mentors influence career decisions regarding which specialty to pursue and how best to enter that field (41). Women in cardiothoracic surgery place more value on the role that their mentors play in providing sponsorship and assistance in networking than their male counterparts do (41). Luc and colleagues found that women in surgical specialties reported more desire than men for mentorship by individuals of the same sex. Therefore, limited access to senior women in the field can hamper progress. One means to circumvent the limitations of traditional mentoring models that rely on local access to surgeons and face-to-face interaction is to harness the power of social media as a vehicle for providing mentorship to a larger audience of junior women by the relatively small number of women leaders $(42,43)$. Social media also lends itself well to cultivating peer-to-peer mentoring interactions, which help combat the feelings of isolation often experienced by women in the field.

Beyond mere mentoring, what really opens the doors to leadership roles and significant academic and clinical advancement are sponsorship and championship. These are entirely different from, and should not be confused with, mentoring and coaching. Sponsorship is the active correlate of mentorship. A sponsor and a champion can be an individual, an organization, or a professional society that advocates for an individual in a way that can be extremely effective in opening doors of opportunity. If the sponsor happens to be an individual in a position of influence, he or she can create pathways to success and leadership for the mentee, for the mid-career person, and for recruiting new talent. A successful sponsor embodies selflessness, a recognition of the unconscious biases that live within all of us, and specific actions toward promoting another individual, which often puts the sponsor's reputation on the line.

Formal leadership training courses are another important means by which women can learn important skills for success at every level. Courses often include learning modules on contract negotiation, salary benchmarks, and promotion processes for those in academia. Several societies offer courses that are not specific to women but nonetheless provide valuable experience. At the 2020 annual meeting of the STS, President Robert Higgins established the inaugural STS Leadership Course with near-equal representation of women and men junior surgeon attendees. Of equal importance was the gender equity among invited speakers and panelists who were highlighted as leaders in our field. The AATS has a similar course conducted at its annual meeting, which has also been very successful. Partnering with other medical societies, including the 
American Society of Clinical Oncology and the American Heart Association, also has promise in learning from best practices and combining efforts, promoting a united front by diverse specialties.

Finally, for the individual surgeon, specialty career enhancement awards that are aimed at women thoracic surgeons have been quite successful. Since 1986, Women in Thoracic Surgery has given various scholarships and grants to women thoracic surgeons and those in training for career development and research funding. Similarly, the Nina Starr Braunwald Award established by the Thoracic Surgery Foundation supports women in academic cardiac surgery positions who completed their residencies within the past 5 years. In the selection process, emphasis is placed on the potential of the applicant as assessed from her prior accomplishments and the quality of her educational experience (44). Additional opportunities for acquiring new technical skills, travel to centers of excellence, and research grants have been supported by important sponsors from industry and represent valuable mechanisms of support.

\section{Conclusions}

Women have made significant strides in representation and accomplishments in the field of thoracic surgery since the first three women diplomates were certified by the ABTS. More women have achieved significant positions of leadership, demonstrating that the culture is slowly changing. Recent milestones include Carolyn Reed becoming the first female president of the Southern Thoracic Society in 2007 and (after being elected posthumously in 2013) the first and only female president of the STS. Most recently, Patricia Thistlethwaite served as the first female president of the Western Thoracic Surgical Association in 2019 and, that same year, Valerie Rusch became the president of the American College of Surgeons.

These milestones are hugely important in highlighting the achievements of champions in our field. They are the product of skill and tenacity embodied by these individuals in an environment that has been unwelcoming at best and overtly hostile at worst. Yet their importance should not be overshadowed by their gender. "Dr. James Barry" was another pioneering surgeon who captured this sentiment in a profound way. He graduated from the prestigious Edinburgh Medical School in 1812 at the young age of 17, then served in the army as a surgeon during the Napoleonic wars. At the time of his death, Barry was discovered to actually be a woman named Dr. Miranda Stewart. A friend is quoted as saying on her behalf, "She chose to be a military doctor. Not to fight for the right of a woman to become one, but simply to be one" (45).

Without any doubt, engagement of leadership and topdown change will be the keys to achieving and maintaining gender equity in our specialty, thereby promoting patient safety and satisfaction, improving clinical outcomes, and fostering innovation. Having leaders invested in the process will ensure a pipeline of talented candidates who have equitable access to advancement and who are supported along the way. As noted by Lawrence Cohn in his presidential address to the AATS, "Persistence is perhaps the most important personal quality in any successful cardiothoracic surgeon" (46). So persistent she shall be!

\section{Acknowledgments}

Stephen N. Palmer, PhD, ELS, contributed to the editing of the manuscript.

Funding: None.

\section{Footnote}

Provenance and Peer Review: This article was commissioned by the editorial office, Fournal of Thoracic Disease for the series "Women in Thoracic Surgery". The article has undergone external peer review.

Conflicts of Interest: Both authors have completed the ICMJE uniform disclosure form (available at http://dx.doi. org/10.21037/jtd.2020.04.13). The series "Women in Thoracic Surgery" was commissioned by the editorial office without any funding or sponsorship. LB served as the unpaid Guest Editor of the series. Dr. OP reports other from W.L Gore and Associates, other from Terumo Aortic, outside the submitted work. The authors have no other conflicts of interest to declare.

Ethical Statement: The authors are accountable for all aspects of the work in ensuring that questions related to the accuracy or integrity of any part of the work are appropriately investigated and resolved.

Open Access Statement: This is an Open Access article distributed in accordance with the Creative Commons Attribution-NonCommercial-NoDerivs 4.0 International License (CC BY-NC-ND 4.0), which permits the noncommercial replication and distribution of the article with 
the strict proviso that no changes or edits are made and the original work is properly cited (including links to both the formal publication through the relevant DOI and the license). See: https://creativecommons.org/licenses/by-nc-nd/4.0/.

\section{References}

1. Pastena JA. Women in surgery. An ancient tradition. Arch Surg 1993;128:622-6.

2. National Library of Medicine. Changing the face of medicine. Available online: https://cfmedicine.nlm.nih. gov/. Accessed March 32020.

3. Kemeny MM. Jonasson, Braunwald, and Morani. Three firsts in American surgery. Arch Surg 1993;128:643-6.

4. Neuhaus SJ. Surgery: no profession for a lady. ANZ J Surg 2016;86:34-8.

5. American Board of Thoracic Surgery. History of the board. Available online: https://www.abts.org/ABTS/ Public/About/History.aspx. Accessed February 242020.

6. Dr. Myra Adele Logan. J Natl Med Assoc 1977;69:527.

7. Donington JS, Litle VR, Sesti J, et al. The WTS report on the current status of women in cardiothoracic surgery. Ann Thorac Surg 2012;94:452-8; discussion 458-9.

8. Rubis L. Women in thoracic surgery. Available online: https://www.ctsnet.org/article/women-thoracic-surgery. Accessed April 7, 2020.

9. Mosca L, Banka CL, Benjamin EJ, et al. Evidence-based guidelines for cardiovascular disease prevention in women: 2007 update. Circulation 2007;115:1481-501.

10. Association of American Medical Colleges. ACGME residents and fellows by sex and specialty, 2017. 2020. Available online: https://www.aamc.org/data-reports/ workforce/interactive-data/acgme-residents-and-fellowssex-and-specialty-2017. Accessed February 242020.

11. Shemin RJ, Ikonomidis JS. Thoracic Surgery Workforce: report of STS/AATS Thoracic Surgery Practice and Access Task Force--Snapshot 2010. Ann Thorac Surg 2012;93:348-55, 355.e1-6.

12. Ikonomidis JS. The Society of Thoracic Surgeons Thoracic Surgery Practice and Access Task Force: 2014 Workforce Report. Ann Thorac Surg 2016;102:2118-25.

13. Rosati CM, Koniaris LG, Molena D, et al. Characteristics of cardiothoracic surgeons practicing at the top-ranked US institutions. J Thorac Dis 2016;8:3232-44.

14. Olive JK, Preventza OA, Blackmon SH, et al. Representation of women in The Society of Thoracic Surgeons authorship and leadership positions. Ann Thorac Surg 2020;109:1598-604.
15. Backhus LM, Kpodonu J, Romano JC, et al. An exploration of myths, barriers, and strategies for improving diversity among STS members. Ann Thorac Surg 2019;108:1617-24.

16. Hu YY, Ellis RJ, Hewitt DB, et al. Discrimination, abuse, harassment, and burnout in surgical residency training. $\mathrm{N}$ Engl J Med 2019;381:1741-52.

17. Templeton K, Nilsen KM, Walling A. Issues faced by senior women physicians: A national survey. J Womens Health (Larchmt) 2020;29:980-8.

18. Association of American Medical Colleges. The 2019 update: The complexities of physician supply and demand: Projections from 2017 to 2032. 2020. Available online: https://www.aamc.org/data-reports/workforce/data/2019update-complexities-physician-supply-and-demandprojections-2017-2032. Accessed February 242020.

19. Association of American Medical Colleges. Percentage change in the number of active physicians by specialty, 2012-17. 2020. Available online: https://www.aamc.org/ data-reports/workforce/interactive-data/percentagechange-number-active-physicians-specialty-2012-17. Accessed February 242020.

20. Mahoney ST, Strassle PD, Schroen AT, et al. Survey of the US surgeon workforce: Practice characteristics, job satisfaction, and reasons for leaving surgery. J Am Coll Surg 2020;230:283-293.e1.

21. Centers for Disease Control and Prevention. Women and heart disease. 2020. Available online: https://www.cdc.gov/ heartdisease/women.htm. Accessed February 242020.

22. Lawton JS. Sex and gender differences in coronary artery disease. Semin Thorac Cardiovasc Surg 2011;23:126-30.

23. Spiliotopoulos K, Price MD, Amarasekara HS, et al. Are outcomes of thoracoabdominal aortic aneurysm repair different in men versus women? A propensity-matched comparison. J Thorac Cardiovasc Surg 2017;154:1203-14.e6.

24. Daoud D, Cheema FH, Morgan JA, et al. Sex-related differences in outcomes of thoracic organ transplantation and mechanical circulatory support. Tex Heart Inst J 2018;45:240-2.

25. Marshall MB, Kohman LJ. Gender and lung transplantation: size matters, does sex? J Thorac Cardiovasc Surg 2004;128:352-3.

26. Tsugawa Y, Jena AB, Figueroa JF, et al. Comparison of hospital mortality and readmission rates for Medicare patients treated by male vs female physicians. JAMA Intern Med 2017;177:206-13.

27. Greenwood BN, Carnahan S, Huang L. Patient-physician gender concordance and increased mortality among 
female heart attack patients. Proc Natl Acad Sci U S A 2018;115:8569-74.

28. Bertakis KD. The influence of gender on the doctorpatient interaction. Patient Educ Couns 2009;76:356-60.

29. Melloni C, Berger JS, Wang TY, et al. Representation of women in randomized clinical trials of cardiovascular disease prevention. Circ Cardiovasc Qual Outcomes 2010;3:135-42.

30. Liu B, Dharmarajan K, Henschke CI, et al. State-level variations in the utilization of lung cancer screening among Medicare fee-for-service beneficiaries: An analysis of the 2015 to 2017 physician and other supplier data. Chest 2020;157:1012-20.

31. Truth Initiative. Tobacco nation: An ongoing crisis. Available online: https://truthinitiative.org/tobacconation. Accessed March 42020.

32. Wakelee HA, Chang ET, Gomez SL, et al. Lung cancer incidence in never smokers. J Clin Oncol 2007;25:472-8.

33. Bellini MI, Graham Y, Hayes C, et al. A woman's place is in theatre: women's perceptions and experiences of working in surgery from the Association of Surgeons of Great Britain and Ireland women in surgery working group. BMJ Open 2019;9:e024349.

34. Backhus LM, Fann BE, Hui DS, et al. Culture of safety and gender inclusion in cardiothoracic surgery. Ann Thorac Surg 2018;106:951-8.

35. Backhus LM, Lui NS, Cooke DT, et al. Unconscious bias: Addressing the hidden impact on surgical education. Thorac Surg Clin 2019;29:259-67.

36. Erhunmwunsee L, Backhus LM, Godoy L, et al. Report from the Workforce on Diversity and Inclusion-The Society of Thoracic Surgeons members' bias experiences. Ann Thorac Surg 2019;108:1287-91.

37. The Rockefeller Foundation. Women in leadership: Tackling corporate culture from the top. 2017. Available

Cite this article as: Preventza O, Backhus L. US women in thoracic surgery: reflections on the past and opportunities for the future. J Thorac Dis 2021;13(1):473-479. doi: 10.21037/ jtd.2020.04.13 online: https://www.rockefellerfoundation.org/report/ women-leadership-tackling-corporate-culture-top/. Accessed February 24, 2020.

38. Cooke DT, Olive J, Godoy L, et al. The importance of a diverse specialty: Introducing the STS Workforce on Diversity and Inclusion. Ann Thorac Surg 2019;108:1000-5.

39. Betancourt JR, Green AR, Carrillo JE, et al. Defining cultural competence: a practical framework for addressing racial/ethnic disparities in health and health care. Public Health Rep 2003;118:293-302.

40. World Economic Forum. The future of jobs: Employment, skills and workforce strategy for the fourth industrial revolution. 2016. Available online: http:// www3.weforum.org/docs/WEF_Future_of_Jobs.pdf. Accessed February 242020.

41. Stephens EH, Goldstone AB, Fiedler AG, et al. Appraisal of mentorship in cardiothoracic surgery training. J Thorac Cardiovasc Surg 2018;156:2216-23.

42. Luc JGY, Stamp NL, Antonoff MB. Social media as a means of networking and mentorship: Role for women in cardiothoracic surgery. Semin Thorac Cardiovasc Surg 2018;30:487-95.

43. Luc JGY, Stamp NL, Antonoff MB. Social media in the mentorship and networking of physicians: Important role for women in surgical specialties. Am J Surg 2018;215:752-60.

44. Benfield JR, Kohman LJ. Mentorship, women thoracic surgeons, and the thoracic surgery foundation for research and education. Ann Thorac Surg 2004;78:1135-6.

45. Wirtzfeld DA. The history of women in surgery. Can J Surg 2009;52:317-20.

46. Cohn LH. What the cardiothoracic surgeon of the twentyfirst century ought to be. J Thorac Cardiovasc Surg 1999;118:581-7. 